\title{
SOME STUDENTS ARE MORE DIFFERENT THAN OTHERS
}

\author{
Hanneke THIEME and Annemiek G C VAN BOEIJEN \\ Faculty of Industrial Design Engineering, Delft University of Technology
}

\begin{abstract}
This exploratory study is about the diversity in styles of learning in the context of product design education at the Faculty of Industrial Design Engineering (Delft University of Technology). We collected data from first year Bachelor students and found that indeed there are differences. We found that most students use the Dreaming Style as dominant style of working. Students who are aware of their personal learning style are more able to use appropriate personal learning skills in each step in the design process. Design tutors can support students more effectively by understanding their own dominant learning style and that of their students.
\end{abstract}

Keywords: personal differences, learning process, design process

\section{INTRODUCTION}

At our Faculty, design projects are playing a major role in supporting students to get hands on design and to learn coping with a variety of difficulties which occur during the process of designing. As design tutors we try our best to teach students to find their way in this complex process. Whether or not our efforts lead to successful students partly depends on individual student's personal traits and characteristics. Since the amount of students at our Faculty is growing while the means of facilitating them are decreasing, it becomes more difficult to work with a student's personal traits. Moreover, coping with personal differences has mainly been associated with an individual student's problems, not with design education. To find out more about this, we carried out an exploratory research into possible ways of coping with personal differences in IDE-students at our Faculty. With this in mind we introduced the Kolb Learning Style Theory to our first year Bachelor students. This theory may be seen as a tool that helps enhance awareness and use of personal differences both for design tutors and students. By introducing this tool, we also wanted to find out more about how students and design tutors can find new ways of helping students with difficulties in designing.

\section{RESEARCH APPROACH}

2.1 Our starting point: introducing the Kolb Learning Style Theory

David Kolb's Learning Styles Model and Experiential Learning Theory have first been published in 1984 [1]. In our view this model is particularly useful for design education because both the learning of theory as well as the acquiring of practical skills are part of this model. Kolb defines four distinctive learning styles which are based on a four-stage learning cycle. Thus the model offers a way of understanding individual people's learning styles and also provides us with an explanation of how good learning takes place. Kolb states that good learning requires going through the whole circle, which is 
based on two axes, in which four types of learning activities take place: concrete experiences provide a basis for observations and reflections, which can be turned into abstract concepts, which produce new ideas which can be actively tested, thus creating new concrete experiences. The model also provides us with a four type definition of learning styles: Dreaming Style, Thinking Style, Decision Maker Style, and Doing Style.

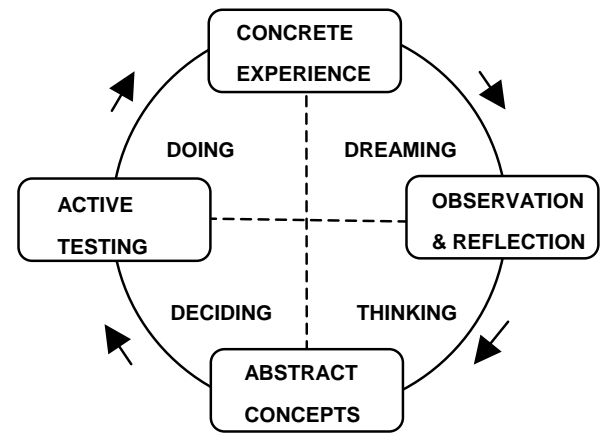

Figure 1 Learning Circle and learning Styles, based on Kolb

Kolb says that people naturally prefer one of these four learning styles (=dominant learning style). He also states that the ability to switch between different styles does not come easy or naturally to most people.

For this exploratory research and considering the research questions and a description of the learning styles [2] we regarded the Kolb learning styles as a set of personal learning skills and obstructions that may help or hinder students to become better designers.

1. Dreaming Style. People who dominantly use this style tend to prefer watching over doing and gather information and use imagination to solve problems. They typically are able to use the following skills: able to use fantasy; able to create many new ideas and to work with alternatives; able to look at problems from different angles; able to manage their own and other people's emotions; able to work in groups and give and receive feedback with an open mind. The skill of making decisions typically is not included in this learning style. Obstructions to learn to use this learning style can be: not taking enough time to think; not willing to write things down; not able or willing to visualize; not able or willing to use fantasy; not able or willing to think carefully and precisely.

2. Thinking Style. People who dominantly use this style tend to prefer a concise, logical approach, in which ideas and concepts are more important than people. They typically are able to use the following skills: able to create and work with theoretical models; able to understand information and to logically organise this information; able to draw conclusions; able to work carefully and accurate. Being able to find practical purposes typically is not included in this learning style. Obstructions to learn to use this learning style can be: taking things for granted unquestioningly; preference for intuition and subjectivity; dislike of structured approach of problems; strong preference for spontaneity; underdeveloped powers of abstraction.

3. Decision Maker Style. People who dominantly use this style tend to look for solutions to practical issues and to be less concerned with people. They typically are able to use the following skills: able to find practical uses for ideas and theories; able to quickly solve problems; able to make decisions by finding solutions to questions and problems; able to experiment with new ideas and to simulate; able to work with practical applications. Being able to select the proper problem and stay focussed on it is 
typically not included in this learning style. Obstructions to learn to use this learning style can be: preference for ideal instead of practical solutions; enjoying interesting detours; lack of focus; perfectionism.

4. Doing Style. People who dominantly use this style tend to work are 'hands-on' and to rely on intuition rather than logic. They typically are able to use the following skills: able to use other people's analysis; able to take a practical, experiential approach; able to go for new challenges and experiences; able to set targets and carry out plans; able to work in teams; able to work by 'trial and error'. Being able to choose a good angle to work from is typically is not included in this learning style. Obstructions to learn to use this learning style can be: fear of failure; taking life very seriously; strong wish to think things over; fear of trying something new or something unprecedented.

\subsection{What did we want to know?}

The general research questions were:

1. Are there differences in learning styles between first year Bachelor students?

2. If yes, how do they differ?

3. How can this knowledge be used by students and tutors?

\subsection{How did we search for answers?}

Since September 2003 each individual first year Bachelor student ( $N=1297$ ) was asked to fill out the Kolb questionnaire in order to find out their dominant learning style. At our Faculty these students (except very few) have Dutch nationally and most of them are 18 or 19 years old. Almost all students have the same educational background, in terms of knowledge as well as in terms of study skills. Therefore we used a Dutch translation of the questionnaire while no other explanations were considered necessary. In addition to this, at the start of the Academic Year in September 2007, we created a one-and-a-half hour workshop on Kolb which was presented to the 317 first year students in their 12 studios during their design education.

The workshop consisted of three parts. Firstly, focusing on the first and second research question, students had to fill out the questionnaire. Secondly, students were presented with a short lecture on the Kolb Learning Theory. Immediately following this and focusing on research question no. 3, the students took part in a group discussion, where they were encouraged to discuss their personal outcome with fellow students and to think of suggestions how to use their freshly gained knowledge about themselves and their fellow students in the design work they were presently doing. Design tutors were asked to be present during the workshop, to also fill out the questionnaire and to take part in the discussions.

After 3-6 weeks a selected group of 20 students were interviewed individually. These were students who reported difficulties in doing the design assignments. These interviews were structured open attitude interviews [3] and took about 20 minutes each.

\section{RESULTS}

\subsection{What facts did we find?}

The questionnaires were evaluated and profiles were built for each group of students. Surprisingly, most of the students (44\%) use the Dreaming Style as dominant learning style. Students who use the Decision Maker Style are rare (5.2\%). We also found that the occurrence of Doing Style is $17,5 \%$, of Thinking Style $19.4 \%$ and that $9.8 \%$ of the students are dominant on 2 learning styles, while $4.1 \%$ are dominant on all four. 


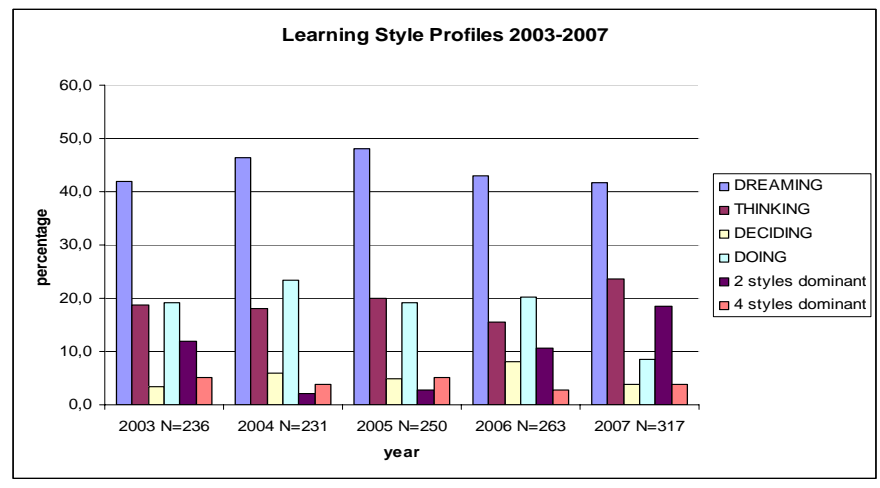

Figure 2 Dominant Learning Styles in first year Bachelor IDE 2003 - 2007

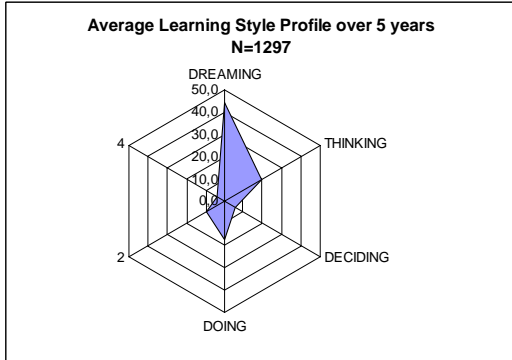

Figure 3 Average dominant learning styles in first year IDE Bachelor students 2003-2007

\subsection{What else did we become aware of?}

Students were encouraged to discuss how to use their Kolb knowledge about themselves and other students while doing their design projects. From this we learned a few lessons. 1. Students were very surprised to learn that it is possible to look at themselves as a learner and a designer in a structured and useful manner. They were surprised to recognise themselves in the outcome of the questionnaire and lively discussions started immediately. Lots of questions were asked and lots of tentative answers given. Students tried to analyze the strong and weak points of their default learning style in relation to the design work they were doing.

2. Students were surprised that different learning style exists and that other students may have other styles of learning. The description of skills and especially the list of obstructions were very evocative and students immediately started to think how this would apply to themselves and their work.

3. Students showed much interest in other people's questionnaire result. They talked about the differences between one person's initial approach of problems and problem solving skills and those other persons. Also they discussed how this might influence group work. For instance being in a team with people who all have a different learning style may cause trouble getting started. Once started, it might turn into an advantage, because many types of skills are present. Being in a team with all people having the same dominant learning style might produce an immediate mutual understanding of what to do and how, but might also give difficulties because some important skills are not present in the team.

4. Students learned that is it possible and probably quite important to give attention not only to their design work but also to themselves as a designer. Having some knowledge about one's dominant learning style might help to analyze problems that 
they encounter in doing their design work. Moreover, having knowledge of other learning styles may help solve problems by using other skills that do not come naturally.

\subsection{What did the Interviews with students tell us?}

Case 1. Student with dominant Dreaming Style fails to create a design goal.

The student describes the product in abstract terms that have something to do with values that are important to him, and very inspiring. However, he is not able to be specific, he expresses doubts about next steps and the progress hampers. The student was supported by helping him to shift to the thinking style. This was done by scanning the list of thinking style skills, explaining how to apply these skills, and by asking very specific analytic questions, thus helping him to structure his thoughts and write down answers within a concrete timeframe

Case 2. Student with dominant Decision Maker Style feels a lack of ideas and creativity. The student has collected a lot of information, has been able to analyze very well and to draw conclusions. She has written a good report but.... no ideas come up for design solutions. This student was supported by helping her to shift to the doing style, explaining that no perfect solutions exist and that she can use her conclusions in any way she likes. She was encouraged 'to give it a try', to do something, no matter what, to make "educated guesses" and to be more playful, not taking her report too seriously. In addition to this, she also was helped by offering her some creativity techniques.

Case 3. Student with dominant Dreaming Style shows insufficient progress in designing. This student has started the assignment very well. He has gathered information and has lots of creative product ideas. He produces many interesting drawings and pieces of text. But after a few weeks the process stops and he fails to make progress. The student was supported by helping him to shift to the decision maker style. This was done by explaining to him that he should stop producing more interesting ideas, but instead should focus on a few of his best ideas and start to detail them. At first the student flatly refused to do this. It then turned out that he was afraid of loosing his creativity. After suggesting that detailing a product can be a creative activity too, he then understood that having a focus does not contradict being creative.

From these interviews we learned three lessons:

1. Although students tend to take their personality for granted and do not look at it as a set of changeable personal skills, all of them could indeed be encouraged to try to adopt other learning styles. By analyzing the individual's problem and searching the list of skills and obstructions, students can be helped to find new ways of coping with the problem. They also can be encouraged to experiment with new behaviour that does not come to them naturally, especially by giving concrete suggestions as to how new behaviour could be expressed.

2. When first getting acquainted and trying to work with Kolb, students seemed to be most interested in the lists of possible obstructions, probably because it is easier for a student to recognise their problem than to recognise useful new skills. Starting from there and then helping to add new skills to the skills already present, seems easier for students than directly starting with helping students to develop new skills [4]. For some tutors this might require extra tutorial skills.

3. For some students, trying to adopt skills from other learning styles turned out to be extremely difficult. These students behaved indifferently, or became very upset or even started to cry. Before going on, the tutor should pay immediate attention to this. To do this, the tutor might need extra consultation skills [5]. 


\section{CONCLUSIONS AND DISCUSSION}

1. There are differences in learning styles between $1^{\text {st }}$ year Bachelor students at IDE. We see that almost half of our students use the same learning style, while others use one that is not commonly found: indeed some students are more different than others.

2. Most students use the Dreaming Style as a dominant style of working.

We were very surprised and we still wonder: is this typical for industrial designers? If yes, so what? It might play a role in multi-disciplinary teams. We suggest making a comparison with students from other, less creative and integrative professions (like dental surgery). Also we suggest carrying out a study of group performance in groups with members of the same/different dominant learning styles. It also might play a role in tutoring and our general teaching environment. We suggest taking a closer look into tutor-student interactions with or without the same learning style.

3. Students who are aware of their learning style are more able to use appropriate personal skills in each step in the design process.

Students are already learning to think about and work on their design assignments in a structured manner. With Kolb, they also become able to take themselves into consideration as a designer. The happy conclusion therefore may be that students can learn to look at and work with themselves as a designer exactly as we would like them to do with their design projects. We would suggest some more experimenting with this. At our Faculty the product design process theory according to Roozenburg and Eekels is widely used [6]. At first glance, the learning styles seem to fit in. However, this theory suggests a rather fixed beginning and in essence a quite linear approach of designing, while Kolb suggests that it is effective to start with one's dominant learning style. We suggest making a comparison between both models to find out more about this.

4. Design tutors can support students more effectively by understanding their own learning style and that of their students.

To maximize the effects it is recommended that tutors too fill out the questionnaire (and some of them may be astonished by their findings). To further profit some extra training in consultations skills for teachers is recommended.

\section{REFERENCES}

[1] Kolb, D.A. Experiential Learning: Experience as the source of learning and development. Upper Saddle River, New Jersey, Prentice Hall, 1984

[2] Richmond, A.S. and Cummings, R. Implementing Kolb’s learning styles into online distance education. International Journal of Technology in Teaching and Learning, 1, pp 45-54, 2005.

[3] Vrolijk, A. Gesprekstechniek, Bohn Stafleu Van Loghum, Houten, 1991

[4] Steens, R. Menselijke communicatie, Interaktie Akademie, Antwerpen, 1993.

[5] Cladder, H. Oplossingsgerichte korte psychotherapie, Harcourt BV, Amsterdam, 2005.

[6] Roozenburg, N.F.M., Eekels, J., Product Design, Fundamentals and Methods, Wiley, Chichester, UK, 1995.

Hanneke J C THIEME

Faculty of Industrial Design Engineering

Delft University of Technology

Landbergstraat 15

2628 CE Delft

j.c.thieme@tudelft.nl

(0031) (0)15 2782941
Annemiek G C VAN BOEIJEN

Faculty of Industrial Design Engineering

Delft University of Technology

Landbergstraat 15

2628 CE Delft

a.g.c.vanboeijen@tudelft.nl

(0031) (0)15 2782749 